\title{
Aplicabilidade da terapia fotodinâmica antimicrobiana na eliminação do Enterococcus faecalis
}

\author{
Applicability of antimicrobial photodynamic therapy in the elimination of Enterococcus faecalis \\ Aplicabilidad de la terapia fotodinámica antimicrobiana en la eliminación del Enterococcus faecalis \\ Thamyres Maria Silva SIMÕES ${ }^{1}$ \\ Maria das Graças Barbosa da SILVA ${ }^{1}$ \\ José de Alencar FERNANDES NETO ${ }^{1}$ \\ Ana Luzia Araújo BATISTA ${ }^{1}$ \\ Maria Helena Chaves de Vasconcelos CATÃO \\ ${ }^{I}$ Discentes do Programa de Pós-Graduação em Odontologia, Departamento de Odontologia, Universidade Estadual da Paraíba, \\ UEPB, 58429-500, Campina Grande - PB, Brasil \\ ${ }^{2}$ Professora Doutora do Programa de Pós-Graduação em Odontologia, Departamento de Odontologia, Universidade Estadual da Paraíba, \\ $U E P B, 58429-500$, Campina Grande - PB, Brasil
}

\section{Resumo}

Introdução: A endodontia é uma especialidade odontológica que visa promover a saúde dentária por meio da eliminação de microorganismos capazes de causar agressões pulpares. A terapia fotodinâmica antimicrobiana, apresenta-se como uma alternativa coadjuvante ao tratamento endodôntico convencional para eliminação dos micro-organismos resistentes ao preparo-químico-mecânico. Objetivo: Explorar a literatura dando enfoque ao mecanismo de ação e aplicabilidade da aPDT na eliminação do Enterococcus faecalis. Material e método: Realizou-se uma revisão de literatura conduzida através do acesso às bases de dados eletrônicos Medline/Pubmed e Scielo utilizando isoladamente ou em associação as palavras-chaves "Photodynamic Therapy", "Enterococcus faecalis" e "Endodontic", no período de 2007 a 2017, totalizando 392 artigos. Resultados: A eliminação de forma eficaz de bactérias, Enterococcus faecalis, são vantagens atribuídas à terapia fotodinâmica, no entanto, a literatura evidencia a necessidade de utilizá-la associada a outras formas de tratamento. Conclusão: É necessária a padronização dos protocolos para que se obtenha dados mais esclarecedores sobre a eficácia da terapia fotodinâmica na eliminação do Enterococcus faecalis.

Descritores: Endodontia; Fotoquimioterapia; Enterococcus faecalis.

\section{Abstract}

Introduction: Endodontics is a dental specialty that aims to promote dental health by eliminating microorganisms capable of causing pulpal aggressions. Photodynamic antimicrobial therapy is an alternative to conventional endodontic treatment for the elimination of microorganisms resistant to chemical preparation. Objective: To explore the literature focusing on the mechanism of action and applicability of aPDT in the elimination of Enterococcus faecalis. Material and method: A literature review was conducted through access to the Medline / Pubmed and Scielo electronic databases using the keywords "Photodynamic Therapy", "Enterococcus faecalis" and "Endodontic". Results: The effective elimination of bacteria, Enterococcus faecalis, are advantages attributed to photodynamic therapy, however, the literature evidences the need to use it associated with other forms of treatment. Conclusion: Standardization of protocols is necessary to obtain more clarifying data on the efficacy of photodynamic therapy in the elimination of Enterococcus faecalis.

Descriptors: Endodontics; Photochemotherapy; Enterococcus faecalis.

\section{Resumen}

Introducción: La endodoncia es una especialidad odontológica que busca promover la salud dental a través de la eliminación de microorganismos capaces de causar agresiones pulpares. La terapia fotodinámica antimicrobiana, se presenta como una alternativa coadyuvante al tratamiento endodóntico convencional para la eliminación de los microorganismos resistentes al preparado-químicomecánico. Objetivo: Explorar la literatura centrándose en el mecanismo de acción y aplicabilidad de la aPDT en la eliminación del Enterococcus faecalis. Material y método: Se realizó una revisión de literatura conducida a través del acceso a las bases de datos electrónicos Medline / Pubmed y Scielo utilizando aisladamente o en combinación las palabras clave "Photodynamic Therapy", "Enterococcus faecalis" y "Endodontic". Resultados: La eliminación eficaz de bacterias, Enterococcus faecalis, son ventajas atribuidas a la terapia fotodinámica, sin embargo, la literatura evidencia la necesidad de utilizarla asociada a otras formas de tratamiento. Conclusión: Es necesaria la estandarización de los protocolos para que se obtengan datos más claros sobre la eficacia de la terapia fotodinámica en la eliminación del Enterococcus faecalis.

Descriptores: Endodoncia; Fotoquimioterapia; Enterococcus faecalis.

\section{INTRODUÇÃO}

A endodontia evoluiu substancialmente com o desenvolvimento e adoção de novas tecnologias e materiais, entretanto, a maioria dos insucessos endodônticos está relacionada com a resistência de micro-organismos ao preparo químico-mecânico (PQM) ou a medicação intracanal ${ }^{1}$.

O Enterococcus faecalis, bactéria Grampositiva anaeróbia facultativa, está frequentemente (22 a 77\% dos casos) associado ao insucesso no tratamento endodôntico. Estes micro-organismos podem penetrar facilmente nos túbulos dentinários dos canais radiculares, dificultando a sua desinfecção. Nesse contexto, a Antimicrobial Photodynamic Therapy (aPDT) desponta como uma nova terapia coadjuvante ao tratamento endodôntico ${ }^{2,3}$.
A atividade da aPDT baseia-se na combinação de um fotossensibilizador não tóxico e de uma luz visível com comprimento de onda apropriado, que na presença de oxigênio ambiente é ativado e pode promover uma resposta fototóxica. Durante aPDT, apenas as células com acumulação seletiva do fotossensibilizador, que também recebem exposição à luz, são mortas ${ }^{4-6}$.

Em casos de resistência microbiana aos procedimentos de tratamento de rotina, aPDT pode ser eficiente na eliminação e redução de microorganismos existentes no canal principal, canais laterais e túbulos dentinários que podem causar infecção pulpar e periapical ${ }^{7}$.

Diante do exposto, o presente artigo tem como objetivo explorar através da revisão de 
literatura a aplicabilidade da aPDT e eliminação do E. faecalis no tratamento endodôntico.

\section{MATERIAL E MÉTODO}

Realizou-se uma revisão de literatura conduzida através do acesso às bases de dados eletrônicos Medline/Pubmed e Scielo utilizando isoladamente ou em associação as palavras-chaves "Photodynamic Therapy", "Enterococcus faecalis" e "Endodontic", totalizando 392 artigos.

Os trabalhos científicos encontrados foram submetidos à triagem inicial, onde foi realizada a filtragem dos artigos publicados em revistas científicas no período de 2007 a 2017. Na triagem secundária os artigos pré-selecionados foram lidos na íntegra e submetidos à avaliação dos seguintes aspectos: procedência das revistas, indexações, detalhamento metodológico e consistência dos resultados apresentados pelos autores, sendo excluídos os temas divergentes ao foco da análise, os artigos anteriores a 2007, revisões de literatura, resumos publicados em anais de eventos científicos e estudos in vitro.

Dos artigos encontrados, 25 foram préselecionados e 4 foram incluídos na revisão. A Figura 1 resume a estratégia de seleção dos artigos para esta revisão.

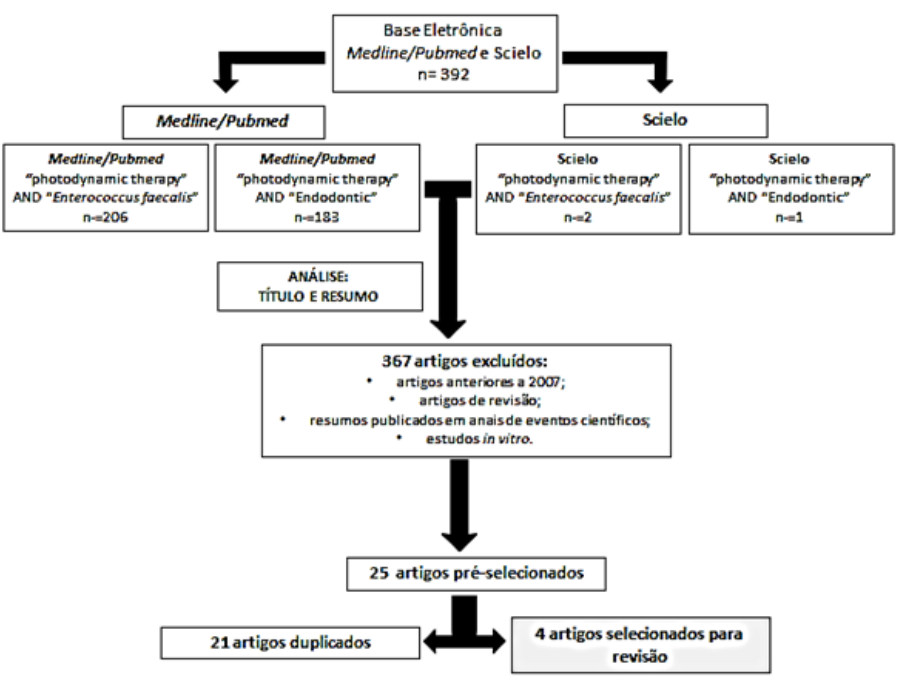

Figura 1. Fluxograma com a estratégia de seleção para a inclusão dos artigos.

\section{REVISÃO DA LITERATURA}

O E. faecalis é uma bactéria anaeróbia facultativa, Gram-positiva, frequentemente encontradas em canais radiculares de dentes com insucesso endodôntico, sendo a espécie predominante em casos de retratamento chegando a representar de $38 \%$ a $70 \%$ da microbiota do sistema de canais radiculares. ${ }^{8}$.

Não é um microrganismo residente da microbiota da cavidade oral indicando que uma infecção exógena foi responsável pela contaminação do sistema de canais. O insucesso endodôntico devese a um processo de seleção dependente da resistência específica do E. faecalis ao preparo químico-mecânico (PQM) e à medicação intracanal, como o hidróxido de cálcio. Tal particularidade devese à capacidade que a bactéria possui de sobreviver em condições ecológicas modificadas no interior do sistema de canais radiculares, em um meio nutricional restrito, no qual as relações bacterianas são mínimas ${ }^{9-14}$.

Estudos têm revelado um aumento surpreendente da resistência antimicrobiana das bactérias que são comumente encontradas nos canais radiculares de dentes com infecção endodôntica. A resistência aos agentes antimicrobianos pode ser adquirida por uma mutação no DNA existente ou por aquisição de um novo DNA, onde bactérias como o E. faecalis, podem transmitir genes entre populações de uma mesma espécie ou de espécies diferentes ${ }^{14-18}$.

Apesar da incidência de cepas resistentes maior em infecções hospitalares ou sistêmicas, estudos através de isolados bacterianos de infecções endodônticas têm demonstrado o surgimento de resistência bacteriana, principalmente a terapia convencional utilizada em procedimentos odontológicos $^{16,17,19}$.

A aPDT, surge como uma promissora terapia antimicrobiana, sendo considerada um suplemento aos protocolos tradicionais para a desinfecção do canal, podendo ser combinada com a instrumentação mecânica usual e antimicrobianos químicos ${ }^{20-21}$. Esta terapia é baseada na aplicação de um fotossensibilizador não tóxico, uma fonte de luz e oxigênio para induzir danos às bactérias ${ }^{22}$.

Os fotossensibilizadores derivados das fenotiazinas têm sido amplamente empregados nas pesquisas envolvendo aPDT no tratamento endodôntico. As fenotiazinas são compostos heteroaromáticos tricíclicos, corantes azuis, como o corante azul de toluidina e o azul de metileno ${ }^{23-26}$. Segundo George e Kishen ${ }^{27,28}$, aPDT pode destruir a integridade funcional das paredes celulares bacterianas, do DNA e das proteínas da membrana de E. faecalis, sendo os danos influenciados pelo fotossensibilizador.

Diferentes fontes de luz podem ser utilizadas em aPDT endodôntica, como o Light Emitting Diode (LED) ou Light Amplification by Stimulated Emission of Radiation (Laser). Atualmente são utilizados lasers de diodo, emitindo no espectro do vermelho em baixa intensidade, por serem bem absorvidos pelos tecidos biológicos. Uma fonte de luz alternativa são os LEDs, que podem ser utilizados como fontes de ativação em aPDT, apresentando um baixo componente térmico e luz monocromática, com banda estreita de comprimento de onda ${ }^{29,30}$.

A aPDT apresenta-se como uma técnica de 
fácil e rápida aplicação clínica, podendo ser utilizada em tratamentos, complementando a antissepsia do sistema de canais radiculares, devendo os cirurgiõesdentistas ficarem atentos quanto aos seguintes critérios: tempo de aplicação, níveis de energia e local de emissão.

\section{RESULTADOS E DISCUSSÃO}

Após a busca sistematizada, foram selecionados 4 artigos que resultaram em uma ampla discussão focada nas suas particularidades (Tabela 1).

A combinação de terapia endodôntica convencional seguida de aPDT é altamente eficaz na redução da carga bacteriana em canais radiculares infectados. No entanto, o estudo de Garcez et al. ${ }^{31}$ apresentou em um segundo tratamento aPDT, uma redução bacteriana mais eficaz do que aquela observada em uma primeira aplicação. Os resultados dos estudos in vivo para os tratamentos combinados foram ainda melhores, o tecido circundante pode promover a retrodifusão da luz, aumentando assim o número de fótons disponíveis para a fotoreação.

A razão para esta observação é provavelmente a presença de um biofilme menos complexo em comparação à infecção inicial. Outro motivo, seria o pH alcalino promovido pela utilização de hidróxido de cálcio entre as consultas, o que melhora a produção de oxigênio síngleto.

A desinfecção do canal com aPDT ou hidróxido de cálcio após preparo químico-mecânico (PQM) convencional pode efetivamente reduzir a contagem de colônias. Segundo Ahangari et al. ${ }^{32}$, não existe diferença significativa entre os dois métodos mencionados, sendo aPDT com laser de diodo (810 $\mathrm{nm}$ ), uma alternativa adequada à utilização do hidróxido de cálcio em um tratamento de sessão única, bem como em dentes com lesões periapaicais como observado por Asnaashari et al. ${ }^{6}$

Quando associada à endodontia regenerativa, como no estudo de Johns et al. ${ }^{33}$ aPDT é capaz de promover a revitalização de dentes imaturos com polpas necróticas através da desinfecção total do canal, já que as células bacterianas são geralmente mais suscetíveis aos fotossensibilizadores ativados por luz.

\section{CONCLUSÃO}

Embora aPDT não possa ser usada de forma isolada nas infecções pulpares, diversos estudos a evidenciaram como coadjuvante eficaz no tratamento endodôntico, podendo ser utilizada também como alternativa à antibioticoterapia. Há ausência de padronização metodológica o que limita a confiabilidade dos estudos que se propõem a avaliar a eficácia da aPDT no tratamento das infecções pulpares e na eliminação do E. faecalis.
Tabela 1. Análise dos artigos selecionados

\begin{tabular}{|c|c|c|c|}
\hline $\begin{array}{l}\text { AUTOR/ } \\
\text { ANO }\end{array}$ & OBJETIVO & DETALHES DO ESTUDO & CONCLUSÃO \\
\hline $\begin{array}{c}\text { Asnaashari } \\
\text { et al. }{ }^{6} \\
(2016)\end{array}$ & $\begin{array}{c}\text { Comparar a } \\
\text { eficácia } \\
\text { antibacteriana } \\
\text { do laser de } \\
\text { diodo } 810 \mathrm{~nm} \text { e } \\
\text { a terapia } \\
\text { fotodinâmica } \\
\text { (aPDT) na } \\
\text { redução da } \\
\text { microflora } \\
\text { bacteriana no } \\
\text { retratamento } \\
\text { endodôntico de } \\
\text { dentes com } \\
\text { lesão } \\
\text { perirradicular. }\end{array}$ & 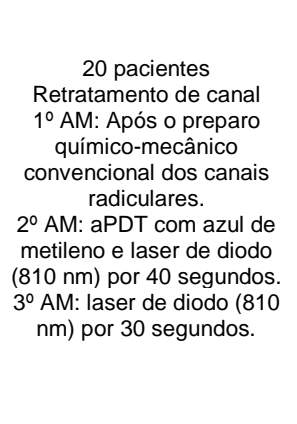 & $\begin{array}{l}\text { aPDT e o laser } \\
\text { de diodo (810 } \\
\text { nm) são } \\
\text { métodos } \\
\text { eficazes para a } \\
\text { desinfecção do } \\
\text { canal radicular } \\
\text { e apresentam } \\
\text { menor risco } \\
\text { térmico na } \\
\text { dentina } \\
\text { radicular. }\end{array}$ \\
\hline $\begin{array}{l}\text { Garcez } \\
\text { et al. } \\
(2007)\end{array}$ & $\begin{array}{c}\text { Comparar o } \\
\text { efeito } \\
\text { antimicrobiano } \\
\text { da terapia } \\
\text { fotodinâmica } \\
\text { (aPDT) em } \\
\text { associação } \\
\text { com o } \\
\text { tratamento } \\
\text { endodôntico. }\end{array}$ & $\begin{array}{c}20 \text { pacientes } \\
\text { Polpa necrótica e } \\
\text { periodontite periapical } \\
\text { Amostras microbiológicas } \\
\text { (AM) foram realizadas após } \\
\text { o acesso ao canal, terapia } \\
\text { endodôntica e aPDT. } \\
\text { 10 AM: Acesso do canal + } \\
\text { remoção do tecido } \\
\text { necrótico (K\#10)+ irrigação } \\
\text { (1 ml de solução salina } \\
\text { estéril). } \\
20 \text { AM: Instrumentação } \\
\text { manual + irrigação ( } 10 \mathrm{ml} \\
\mathrm{NaCl} 2,5 \%+10 \text { mL } \mathrm{H}_{2} \mathrm{O}_{2} \% \\
\text { 3\%) + irrigação final }(5 \mathrm{~mL} \\
\text { de EDTA a } 17 \%) .0 \text { canal } \\
\text { foi irrigado com } 5 \mathrm{~mL} \text { de } \\
\text { solução salina estéril. } \\
\text { 3o AM: } 0,5 \text { ml de PS dentro } \\
\text { do canal por } 2 \text { min }+ \text { laser } \\
\text { de diodo acoplado com a } \\
\text { fibra óptica por } 240 \\
\text { segundos. }\end{array}$ & $\begin{array}{l}\text { O uso de aPDT } \\
\text { adicionado ao } \\
\text { tratamento } \\
\text { endodôntico } \\
\text { leva a uma } \\
\text { diminuição } \\
\text { aumentada da } \\
\text { carga } \\
\text { bacteriana e } \\
\text { pode ser uma } \\
\text { abordagem } \\
\text { apropriada para } \\
\text { o tratamento de } \\
\text { infecções orais. }\end{array}$ \\
\hline $\begin{array}{l}\text { Ahangari } \\
\text { et al. }^{32} \\
(2017)\end{array}$ & $\begin{array}{c}\text { Comparar } \\
\text { eficácia } \\
\text { antibacteriana } \\
\text { da terapia com } \\
\text { hidróxido de } \\
\text { cálcio como } \\
\text { método padrão } \\
\text { e aPDT por } \\
\text { laser de diodo } \\
\text { com } \\
\text { comprimento } \\
\text { de onda de } 810 \\
\text { nm + azul de } \\
\text { metileno (MB) } \\
\text { na desinfecção } \\
\text { do canal } \\
\text { radicular dos } \\
\text { dentes com } \\
\text { lesão } \\
\text { perirradicular. }\end{array}$ & $\begin{array}{c}20 \text { pacientes; retratamento } \\
\text { de canal; lesão } \\
\text { perirradicular } \\
\text { 10 AM: Após o preparo } \\
\text { químico-mecânico } \\
\text { convencional do canal } \\
\text { radicular (instrumentos } \\
\text { manual e rotativo e } 2,5 \% \text { de } \\
\text { NaOCl). } \\
\text { 20 AM: Os espécimes do } \\
\text { grupo } 1 \text { foram submetidos a } \\
\text { aPDT (laser de diodo } 808 \\
\text { nm + } 50 \text { mg / ml de azul de } \\
\text { metileno). } \\
\text { 3\%AM: O hidróxido de cálcio } \\
\text { foi utilizada no grupo } 2 \\
\text { durante uma } 1 \text { semana. }\end{array}$ & $\begin{array}{l}\text { aPDT e terapia } \\
\text { com hidróxido } \\
\text { de cálcio } \\
\text { apresentaram a } \\
\text { mesma eficácia } \\
\text { antimicrobiana } \\
\text { em E. faecalis } \\
\text { e C. albicans. }\end{array}$ \\
\hline $\begin{array}{l}\text { Johns } \\
\text { et al. }^{33} \\
(2014)\end{array}$ & $\begin{array}{c}\text { Descrever uma } \\
\text { nova proposta } \\
\text { de } \\
\text { revascularizaçã } \\
\text { o da polpa com } \\
\text { desinfecção do } \\
\text { espaço do } \\
\text { canal da polpa } \\
\text { usando uma } \\
\text { combinação } \\
\text { única de uma } \\
\text { solução de } \\
\text { fotossensibiliza } \\
\text { ção e luz laser } \\
\text { de baixa } \\
\text { potência. }\end{array}$ & $\begin{array}{c}\text { Criança - } 9 \text { anos } \\
\text { Necrose pulpar } \\
\text { Irrigação do canal (NaCl } \\
5,25 \% \text { ) e seco com pontos } \\
\text { de papel. } \\
\text { A aPDT foi utilizada para } \\
\text { desinfetar o canal radicular } \\
\text { e fibrina rica em plaquetas } \\
\text { foi utilizada para revitalizar } \\
\text { a polpa. } \\
\text { Três milímetros de } \\
\text { agregado de trióxido } \\
\text { mineral cinzento foram } \\
\text { colocados diretamente } \\
\text { sobre o coágulo de plasma. } \\
\text { Após } 3 \text { dias, selado duplo } \\
\text { com materiais de } \\
\text { preenchimentos } \\
\text { permanentes. }\end{array}$ & $\begin{array}{c}\text { A desinfecção } \\
\text { com aPDT } \\
\text { combinada com } \\
\text { fibrina rica em } \\
\text { plaquetas leva } \\
\text { ao } \\
\text { desenvolviment } \\
\text { o de raízes } \\
\text { satisfatório em } \\
\text { dentes } \\
\text { imaturos } \\
\text { necróticos. }\end{array}$ \\
\hline
\end{tabular}

$* \mathbf{A M}=$ Ambiente Microbiano 


\section{REFERÊNCIAS}

1. Siqueira JF, Rôças I. Clinical implications and microbiology of bacterial persistence after treatment procedures. J Endod 2008; 34(11):1291301 e 3.

2. Fouad AF, Zerella J, Barry J, Spangberg LS. Molecular detection of Enterococcus species in root canals of therapy-resistant endodontic infections. Oral Surg Oral Med Oral Pathol Oral Radiol Endod. 2005;99(1):112-18.

3. Amaral RR, Amorim JCF, Nunes E, Soares JÁ, Silveira FF. Terapia fotodinâmica na endodontia: revisão de literatura. RFO. 2010;15(2):207-11.

4. Pfitzner A, Sigusch B W, Albrecht V, Glockmann E. Killing of periodontopathogenic bacteria by photodynamic therapy $\mathrm{J}$ Periodontol. 2004. 75(10):1343-49.

5. Tortora GJ, Funke BR, Case CL. Microbiology an introduction. San Francisco: Pearson Benjamin Cummings; 2010.

6. Asnaashari M, Godiny M, Azari-Marhabi S, Tabatabaei FS, Barati M. Comparison of the antibacterial effect of $810 \mathrm{~nm}$ diode laser and photodynamic therapy in reducing the microbial flora of root canal in endodontic retreatment in patients with periradicular lesions. J Lasers Med Sci. 2016;7(2):99-104.

7. Asnaashari M, Safavi N. Application of low level lasers in Dentistry (Endodontic). J Lasers Med Sci. 2013;4(2):57-66.

8. Maia Filho ET, Maia CCR, Bastos ACSC, Novais TMG. Efeito antimicrobiano in vitro de diferentes medicações endodônticas e própolis sobre Enterococcus faecalis. RGO. 2008;56(1):21-5.

9. Pinheiro ET, Gomes BP, Ferraz CC, Teixeira FB, Zaia AA, Souza Filho FJ. Evaluation of root canal microorganisms isolated from teeth with endodontic failure and their antimicrobial susceptibility. Oral Microbiol Immunol. 2003;18(2):100-3.

10. SchirrmeisterJF, LiebenowAL, Pelz K, WittmerA, Serr A, Hellwig E et al. New bacterial compositions in root-filled teeth with periradicular lesions. J Endod. 2009; 35(2):169-74.

11. Amaral RR, Amorim JCF, Nunes E, Soares JA, Silveira FF. Terapia fotodinâmica na endodontia: revisão de literatura. RFO. 2010;15(2):207-11.

12.Endo MS, Martinho FC, Zaia AA, Ferraz CC, Almeida JF, Gomes BP. Quantification of cultivable bacteria and endotoxin in posttreatment apical periodontitis before and after chemo-mechanical preparation. Eur $\mathrm{J}$ Clin Microbiol Infect Dis. 2012;31(10):2575-83.

13.Zhang C, Hou BX, Zhao HY, Sun Z. Microbial diversity in failed endodontic root-filled teeth. Chin Med J (Engl). 2012;125(6):1163-68.

14.Endo MS, Ferraz CC, Zaia AA, Almeida JF,
Gomes BP. Quantitative and qualitative analysis of microorganisms in root-filled teeth with persistent infection: monitoring of the endodontic retreatment. Eur J Dent. 2013;7(3):302-9.

15. Morrison D, Woodford N, Cookson B. Enterococci as emerging pathogens of humans. Soc Appl Bacteriol Symp Ser. 1997;26:89S-99S.

16.Poeschl PW, Spusta L, Russmueller G, Seemann R, Hirschl A, Poeschl E et al. Antibiotic susceptibility and resistance of the odontogenic microbiological spectrum and its clinical impact on severe deep space head and neck infections. Oral Surg Oral Med Oral Pathol Oral Radiol Endod. 2010; 110(2):151-56.

17. Skucaite N, Peciuliene V, Vitkauskiene A, Machiulskiene V. Susceptibility of endodontic pathogens to antibiotics in patients with symptomatic apical periodontitis. $\mathrm{J}$ Endod. 2010;36(10):1611-16.

18.Endo MS, Signoretti FG, Kitayama VS, Marinho AC, Martinho FC, Gomes BPFA. Culture and molecular detection of Enterococcus faecalis from patients with failure endodontic treatment and antimicrobial susceptibility of clinical isolates. Braz Dent Sci. 2014; 17(3):83-91

19.Al-Ahmad A, Ameen H, Pelz K, Karygianni L, Wittmer A, Anderson AC, et al. Antibiotic resistance and capacity for biofilm formation of different bacteria isolated from endodontic infections associated with root-filled teeth. J Endod. 2014; 40(2):223-30.

20.DiVito E, Lloyd A. ER:YAG laser for 3dimensional debridement of canal systems: use of photon-induced photoacoustic streaming. Dent Today. 2012;31(11):122,124-27.

21.Zhu X, Yin X, Chang JW, Wang Y, Cheung GS, Zhang C. Comparison of the Antibacterial Effect and Smear Layer Removal Using Photon-Initiated Photoacoustic Streaming Aided Irrigation Versus a Conventional Irrigation in Single-Rooted Canals: An In Vitro Study. Photomed Laser Surg. 2013;31(8):371-77.

22. Veerenda NR, Ghandana G, Sehawat S. Photodynamic therapy: review. Indian J Dent Adv. 2009; 1: 46-50.

23.Seal G, Ng Y, Spratt D, Bhatti M, Gulabivala K. An in vitro comparison of the bactericidal efficacy of lethal photosensitization or sodium hyphochlorite irrigation on Streptococcus intermedius biofilms in root canals. Int Endod J. 2002;35(3):268-74.

24. Soukos N, Chen P, Morris J, Ruggiero K, Abernethy A, Som S, et al. Photodynamic therapy for endodontic disinfection. J Endod. 2006; 32(10):979-84.

25.Foschi F, Fontana C, Ruggiero K, Riahi R, Vera A, Doukas A, et al. Photodynamic inactivation of Enterococcus faecalis in dental root canals in 
vitro. Lasers Surg Med. 2007; 39(10):782-87.

26. Fimple J, Fontana C, Foschi F, Ruggiero K, Song $\mathrm{X}$, Pagonis $\mathrm{T}$, et al. Photodynamic treatment of endodontic polymicrobial infection in vitro. $\mathrm{J}$ Endod. 2008; 34(6):728-34.

27. George S, Kishen A. Augmenting the antibiofilm efficacy of advanced noninvasive light activated disinfection with emulsified oxidizer and oxygen carrier. J Endod. 2008;34(9):1119-23.

28. George S, Kishen A. Photophysical, photochemical, and photobiological characterization of methylene blue formulations for light-activated root canal disinfection. J Biomed Opt. 2007;12(3):034029.

29. Meire MA, De Prijck K, Coenye T, Nelis HJ, De Moor RJ. Effectiveness of different laser systems to kill Enterococcus faecalis in aqueous suspension and in an infected tooth model. Int Endod J. 2009;42(4):351-59.

30. Arneiro RA, Nakano RD, Antunes LA, Ferreira GB, Fontes K, Antunes LS. Efficacy of antimicrobial photodynamic therapy for root canals infected with Enterococcus faecalis. J Oral Sci. 2014;56(4):277-85.

31.Garcez AS, Nuñez SC, Hamblin MR, Ribeiro MS. Antimicrobial Effects of Photodynamic Therapy on Patients with Necrotic Pulps and Periapical Lesion. J Endod. 2008;34(2):138-42.

32. Ahangari Z, Mojtahed Bidabadi M, Asnaashari M, Rahmati A, Tabatabaei FS. Comparison of the antimicrobial efficacy of calcium hydroxide and photodynamic therapy against Enterococcus faecalis and Candida albicans in teeth with periapical lesions; an in vivo study. J Lasers Med Sci. 2017;8(2):72-8.

33.Johns DA, Shivashankar VY, Krishnamma S, Johns M. Use of photoactivated disinfection and platelet-rich fibrina in regenerative endodontics. J Conserv Dent. 2014; 17(5):487-90.

\section{CONFLITO DE INTERESSES}

Os autores declaram não haver conflitos de interesse.

AUTOR PARA CORRESPONDENCIA

Maria Helena Chaves de Vasconcelos Catão

mhcvcatao@gmail.com
Submetido em 22/05/2018

Aceito em 27/06/2018 